\title{
Runoff regime estimation at high-elevation sites: a parsimonious water balance approach
}

\author{
E. Bartolini, P. Allamano, F. Laio, and P. Claps \\ Dipartimento di Idraulica, Trasporti e Infrastrutture Civili, Politecnico di Torino, Italy \\ Received: 4 January 2011 - Published in Hydrol. Earth Syst. Sci. Discuss.: 24 January 2011 \\ Revised: 26 April 2011 - Accepted: 16 May 2011 - Published: 30 May 2011
}

\begin{abstract}
We develop a water balance model, parsimonious both in terms of parameterization and of required input data, to characterize the average runoff regime of highelevation and scarcely monitored basins. The model uses a temperature threshold to partition precipitation into rainfall and snowfall, and to estimate evapotranspiration volumes. The role of snow in the transformation of precipitation into runoff is investigated at the monthly time scale through a specific snowmelt module that estimates melted quantities by a non-linear function of temperature. A probabilistic representation of temperature is also introduced, in order to mimic its sub-monthly variability. To account for the commonly reported rainfall underestimation at high elevations, a two-step precipitation adjustment procedure is implemented to guarantee the closure of the water balance.

The model is applied to a group of catchments in the North-Western Italian Alps, and its performances are assessed by comparing measured and simulated runoff regimes both in terms of total bias and anomalies, by means of a new metric, specifically conceived to compare the shape of the two curves. The obtained results indicates that the model is able to predict the observed runoff seasonality satisfactorily, notwithstanding its parsimony (the model has only two parameters to be estimated). In particular, when the parameter calibration is performed separately for each basin, the model proves to be able to reproduce the runoff seasonality. At the regional scale (i.e., with uniform parameters for the whole region), the performance is less positive, but the model is still able to discern among different mechanisms of runoff formation that depend on the role of the snow storage. Because of its parsimony and the robustness in the approach, the model is suitable for application in ungauged basins and for large scale investigations of the role of climatic variables on water availability and runoff timing in mountainous regions.
\end{abstract}

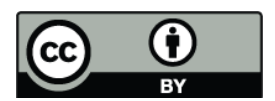

Correspondence to: E. Bartolini (elisa.bartolini@polito.it)

\section{Introduction}

Runoff regime, intended as the sequence of mean monthly runoff values, is a useful indicator of the seasonality of runoff, to be used for the development of water management strategies. The interaction between river ecosystems and human activities, in fact, crucially depends on the timing of runoff peaks and on the periods of low flow, due to the fact that several water uses require water volumes during a specific period of the year (e.g., irrigation, snow making for ski resort). A reliable estimation of runoff regime is particularly important in mountainous regions, as these areas supply fresh water not only in their close neighborhoods but also in the lowlands downstream, where most of the economic and agricultural activities take place. Moreover, the increasing population of the piedmont areas and the vulnerability to climate change shown in mountain regions (e.g., Beniston et al., 1997; Allamano et al., 2009b) raise further important issues for water resources planning and management (e.g., Zierl and Bugman, 2005; Horton et al., 2006; Adam et al., 2009).

Runoff depends on the volume of water supplied to a catchment in terms of rain or snow, as well as on the effects of the other processes involved in the water cycle (i.e., interception, infiltration, evapotranspiration, lakes and aquifers depletion). The transformation of precipitation into streamflow at the basin outlet has been extensively investigated over the last century and various water balance models have been proposed in the literature (e.g., Alley, 1985; Gleick, 1986; Xu et al., 1996; Limbrunner et al., 2006). In particular, models operating at the monthly scale have been extensively used in hydrological applications, as recently reviewed by $\mathrm{Xu}$ and Sing (1998). In fact, thanks to their ease of use and flexibility, these models are suitable for applications at different spatial scales (Gleick, 1986), and they have been extensively used for climate change impact assessment studies in various catchments all over the world (e.g., Xu et al., 1996; Jasper et al., 2004; Wang et al., 2009).

Published by Copernicus Publications on behalf of the European Geosciences Union. 


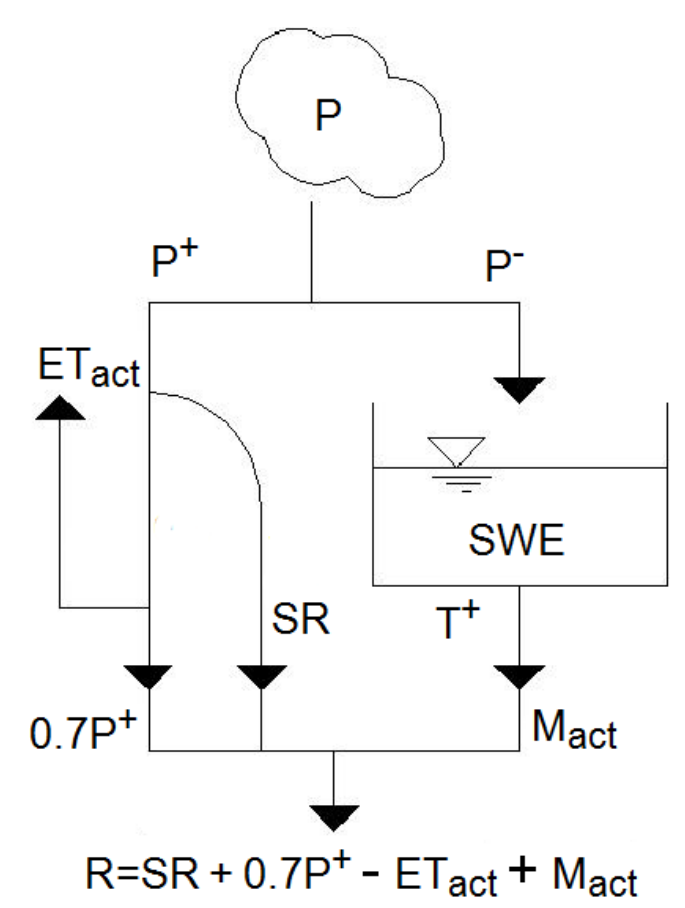

Fig. 1. Qualitative representation of the structure of the water balance model. $P$ is the input to the system, divided into liquid $\left(P^{+}\right)$ and solid $\left(P^{-}\right)$precipitation. SWE is the snow water equivalent contained in the snow storage; $T^{+}\left(T^{-}\right)$represents positive (negative) temperature; SR is the storm runoff; $M_{\text {act }}$ is the snowmelt; $\mathrm{ET}_{\text {act }}$ the actual evapotranspiration and $R$ the runoff.

For high-elevation basins, however, runoff regime estimation remains a challenging problem, due to the need to account for the dynamics of snow accumulation and melt (De Jong et al., 2005). For these areas, specific and more complex water balance models, generally operating at finer time scales (e.g., daily), have been developed, in order to properly describe the snow processes and their effects on the timing and volumes of runoff (e.g., Zappa et al., 2003; Eder et al., 2005; Schaefli et al., 2005). These models attain a good reproduction of daily runoff processes, at the cost of requiring input data with a high temporal resolution (e.g., daily temperature and precipitation). However, it is well known that the density of the monitoring networks tends to decrease with elevation, while measurements errors tend to increase, leading to a precipitation underestimation that in turn affects the quality of the reconstructed runoff (e.g., Milly and Dunne, 2002; Xia and Guoqiang, 2007; Valery et al., 2010). The adoption of complex model structures in the presence of scarce data rises important issues, mainly related to the detrimental effect on the results of having many parameters and few data to estimate them. In fact, while complex models can be useful to investigate the hydrologic processes occurring in specific, well monitored, basins, their validation or extension is generally questionable over regional-scale studies (e.g., Beven, 1989; Limbrunner et al., 2006; Sivakumar, 2008).
The model proposed in this study is conceived to be applied in scarcely monitored basins with the aim of investigating the effects of snow accumulation and melt in the transformation of the precipitation regime into the corresponding runoff regime. The modelling structure is parsimonious in terms of number of parameters to calibrate and provides a simple and controllable framework, suitable to control annual and monthly water budgets over large areas. Parsimony in the hydrological modelling, as proposed by Woods (2003), Mouelhi et al. (2006), Allamano et al. (2009a) among others, allows one to investigate the dominant hydrologic processes in complex orography and data-scarce regions. In this respect, the proposed model differs from those of Zappa et al. (2003), Eder et al. (2005) and Schaefli et al. (2005) among others because it reconstruct the average regimes operating at the monthly time scale. The model partially resembles the one proposed by Woods (2009), with the difference that our analysis relies on measured (not analytical) mean monthly precipitation and seasonal temperature curves. Dealing with observations, the model has to account for the well known problem of precipitation undercatch in high-elevation rain gauges. To this aim, a precipitation correction is considered, obtained as the solution of an inverse problem that uses the difference in the observed and simulated runoff as the variable to be minimized.

\section{Model description}

The model is developed to estimate the average monthly runoff at the catchment scale from spatially averaged monthly precipitation, mean monthly temperature, and some basic geomorphic characteristics of the basin, mainly related to the distribution of the basin area with elevation. The basin is discretized by a regular square grid with cells of approximately $1 \mathrm{~km}^{2}$ characterized by their elevation and latitude.

The model operates at the monthly time scale following the water year (from September to August) and it is based on the partition of monthly precipitation, $P_{j}$, into snow or rain depending on temperature. Given that we consider mean basin precipitation, $P$ is uniformly distributed among cells.

A sketch of the model structure is reported in Fig. 1. According to this scheme, when the temperature is negative, precipitation falls as snow $\left(P^{-}\right)$and fills up the snow storage. During this period of time, precipitation is not involved in direct runoff formation, and no evapotranspiration occurs. When the temperature is positive, precipitation falls as rain $\left(P^{+}\right)$and is divided into two components, $S R$ and $0.7 P^{+}$, representing the storm runoff and the rainfall entering the soil, respectively. The storm runoff represents the fraction of precipitation that enters the stream right after the rainfall and directly contributes to runoff formation (see, e.g., Chow, 1964). In this study, storm runoff is assumed to be the $30 \%$ of the monthly liquid precipitation $P^{+}$and not to vary significantly during the year. The quantity $0.7 P^{+}$constitutes the 
storage for the evapotranspiration, that is driven by positive temperatures, which control also the snow storage depletion. The storage amount not due in evapotranspiration is assumed to reach the basin outlet by the end of the month.

The average monthly runoff is therefore obtained by solving the balance equation

$R_{j}=\mathrm{SR}_{j}+0.7 P_{j}^{+}-\mathrm{ET}_{\text {act }, j}+M_{\text {act }, j}$,

where $R_{j}$ is the runoff in the $j$-th month $(j=1, \ldots, 12)$, $0.7 P_{j}^{+}$is the liquid precipitation entering the soil, $\mathrm{ET}_{\mathrm{act}, j}$ is the actual evapotranspiration and $M_{\mathrm{act}, j}$ is the amount of runoff due to snowmelt.

A constant temperature threshold is assumed to separate snow from rainfall. This represents a rough approximation, but it allows one to apply the water balance model to a vast range of situations and has been extensively used in the literature (see, e.g., Collins, 1998; Limbrunner et al., 2006; Woods, 2009).

Equation (1) is applied to each cell separately, and runoff is then combined to form the discharge at the basin outlet. No lateral flow between cells is considered. Evapotranspiration from snowcover, sublimation, rain-on-snow and the effect of the groundwater storage in the runoff formation are neglected.

The water balance is applied at a monthly time scale. However, while this temporal resolution is suitable to characterize runoff seasonality, the assumption of a constant temperature within the month is inappropriate to describe the processes of snow accumulation and melting, which are strongly influenced by the crossing of the freezing temperature, occurring as a consequence of the daily temperature oscillations. For this reason, even in a monthly water balance framework, a description of the sub-monthly temperature variations is desirable (Kling et al., 2006). To provide a simple, yet realistic, representation of the sub-monthly temperature oscillations, a probabilistic description of the within-month temperature variability is introduced. For reason of analytical tractability, the average daily temperature $T$ is assumed to follow a logistic distribution (e.g., Johnson et al., 1995, chapter 23), whose probability density function (pdf) reads

$$
\begin{aligned}
p\left(T ; \mu_{j}, s_{j}\right) & =\frac{e^{-\left(T-\mu_{j}\right) / s_{j}}}{s_{j}\left(1+e^{-\left(T-\mu_{j}\right) / s_{j}}\right)^{2}}= \\
& =\frac{1}{4 s_{j}} \operatorname{sech}^{2}\left(\frac{T-\mu_{j}}{2 s_{j}}\right),
\end{aligned}
$$

where $\mu_{j}$ is the mean monthly temperature and $s_{j}$ is a scale parameter, directly related to the standard deviation of the daily temperature within the month, $\sigma_{j}$, through the following relation:

$s_{j}=\frac{\sqrt{3}}{\pi} \sigma_{j}$.

The standard deviation of the average daily temperatures, $\sigma_{j}$, is assumed to be constant across different months, so that $\sigma_{j}=\sigma\left(\right.$ and $\left.s_{j}=s\right)$, with $j=1, \ldots, 12 ; \sigma$ will be treated as a model parameter to be calibrated.

Based on this description of the within-month variability of temperature, it is possible to identify the fractions of month characterized by negative and positive temperatures. Processes occurring within each month are then considered to operate in parallel, according to temperature conditions. The fraction of month characterized by negative temperatures $\mathrm{NT}_{j}$ is computed as the probability to have $T<0{ }^{\circ} \mathrm{C}$ :

$$
\begin{aligned}
\mathrm{NT}_{j} & =P\left(T<0 ; \mu_{j}, s\right)=\frac{1}{1+e^{-\left(T-\mu_{j}\right) / s}}= \\
& =\frac{1}{2}+\frac{1}{2} \cdot \tanh \left(\frac{T-\mu_{j}}{2 s}\right) .
\end{aligned}
$$

During this time, precipitation falls as snow and no evapotranspiration or direct runoff occur. The remaining part of the month, relative to positive temperatures, lasts for the fraction $\mathrm{PT}_{j}=1-\mathrm{NT}_{j}$, receives liquid precipitation $P_{j}^{+}=P_{j} \cdot \mathrm{PT}_{j}$, and is characterized by snowmelt, storm runoff and evapotranspiration. Each cell of the basin is potentially subjected to both classes of processes, according to the local distribution of temperature.

\subsection{Modelling snow accumulation and melt}

In the model, the snowpack volume is quantified in terms of millimeters of snow water equivalent (SWE) stored in each cell of the basin. The snowpack dynamics follow the equation:

$\mathrm{SWE}_{j}=\mathrm{SWE}_{j-1}-M_{\mathrm{act}, j}+\mathrm{NT}_{j} \cdot P_{j}$,

so that the volume of the current month $j, \mathrm{SWE}_{j}$, is a function of the snowpack of the previous month $j-1, \mathrm{SWE}_{j-1}$, of the losses due to snowmelt, $M_{\text {act, } j}$, and of the amount of new snowfall, $P_{j}^{-}=\mathrm{NT}_{j} \cdot P_{j}$, obtained as the precipitation $P_{j}$ fallen during the fraction of month with negative temperatures $\mathrm{NT}_{j}$.

Snowmelt is estimated by evaluating the monthly potential snowmelt $M_{\mathrm{pot}, j}$ and by comparing it with the snow water equivalent available for melting. The potential snowmelt reflects the available energy and it is modelled as a parabolic function of temperature,

$M_{\mathrm{pot}, j}=c \cdot\left(T_{j}^{+}\right)^{2} \cdot \mathrm{PT}_{j}$,

where $c$ is a coefficient expressing the melting rate, that is, beside $\sigma$, the second model parameter. $\left(T_{j}^{+}\right)^{2}$, which is used as a proxy for melting energy, is the squared average temperature (conditional above zero) and reads

$$
\left(T_{j}^{+}\right)^{2}=\frac{\int_{0}^{\infty} T^{2} p\left(T \mid \mu_{j}, s\right) \mathrm{dT}}{\int_{0}^{\infty} p\left(T \mid \mu_{j}, s\right) \mathrm{dT}}=\frac{-2 s^{2} \operatorname{Li}_{2}\left(-e^{\frac{\mu_{j}}{s}}\right)}{1-\frac{1}{1+e^{\frac{\mu_{j}}{s}}}},
$$

where $\mathrm{Li}_{2}(\cdot)$ is the dilogarithm function (Abramowitz and Stegun, 1964, chapter 27, Spence's integral for $n=2$ ). 
The actual monthly snowmelt, $M_{\mathrm{act}, j}$, is equal to its corresponding potential value when the amount of the stored $\mathrm{SWE}_{j}$ is sufficient to sustain snowmelt; otherwise it equals $\mathrm{SWE}_{j}$ :

$M_{\mathrm{act}, j}=\left\{\begin{array}{lll}M_{\mathrm{pot}, j}, & \text { if } & \mathrm{SWE}_{j} \geq M_{\mathrm{pot}, j}, \\ \mathrm{SWE}_{j}, & \text { if } & \mathrm{SWE}_{j}<M_{\mathrm{pot}, j} .\end{array}\right.$

This formulation represents a variant of the classical degreeday approach (e.g., Hock, 2003), which is based on a relation similar to Eq. (6) but with a linear dependence of potential snowmelt on temperature. The adoption of a quadratic dependence allows one to (roughly) differentiate the snowmelt rate of the cold season from that of the warm season. In fact, one can interpret the parabolic function of Eq. (6) as a standard degree-day approach with melting rate coefficients that vary along the year, resulting in a slower snowmelt when temperature is slightly positive (i.e., during the cold season), and a faster snowmelt for increasing values of $T_{j}^{+}$. In the discussion section it will be shown that this assumption allows one to obtain a better representation of the runoff regime with the same number of parameters of the standard linear degreeday method.

\subsection{Modelling evapotranspiration}

Evapotranspiration is assumed to be dependent only on temperature whereas evaporation from snowmelt and sublimation are neglected (Stössel et al., 2010). Monthly potential evapotranspiration, $\mathrm{ET}_{\text {pot, } j}$, expressed in millimeters, is computed according to the Thornthwaite equation (1948):

$\mathrm{ET}_{\mathrm{pot}, j}=\frac{N_{j}}{12} \cdot 16\left(10 \cdot \frac{T_{j}^{+}}{I}\right)^{a}$

where $T_{j}^{+}$is the average temperature (conditional above zero) obtained as

$T_{j}^{+}=\frac{\int_{0}^{\infty} T p\left(T \mid \mu_{j}, s\right) \mathrm{dT}}{\int_{0}^{\infty} p\left(T \mid \mu_{j}, s\right) \mathrm{dT}}=\frac{s \cdot \ln \left(1+e^{\frac{\mu_{j}}{s}}\right)}{1-\frac{1}{1+e^{\frac{\mu_{j}}{s}}}}$.

In Eq. (9), the fraction $N_{j} / 12$ is a monthly correction factor, dependent on latitude, which is required to adjust actual daylight length (Bras, 1990) and $a$ is a coefficient dependent on $I$, the annual heat index, obtained by combination of the positive mean monthly temperature values $\mu_{j}$,

$I=\max \left[\sum_{j=1}^{k}\left(\frac{\mu}{5}^{1.514}\right) ; 5\right]$,

where $k$ is the number of months characterized by positive mean monthly temperatures. As a consequence of the variability of $k$ on elevation, $I$ assumes low values for highelevation cells, where monthly temperatures are above zero only for short periods in a year (i.e., 1-2 months). This leads to an overestimation of monthly potential evapotranspiration, due to the fact that Thornthwaite's method was not specifically developed for snow-dominated regions. Nevertheless, the parsimony in the Thornthwaite formulation allows one to estimate potential evapotranspiration based only on monthly temperature and makes this approach suitable for our purposes. In order to correct the effect of low temperatures on $I$, heat indices are supposed to take only values greater than $5^{\circ} \mathrm{C}$ (Eq. 11). Following this assumption, the model proves to be able to predict realistic values of evapotranspiration also at high-elevation sites, as detectable from a qualitative comparison with some reference values obtained with the Penman modified approach reported by Henning and Henning (1981).

Monthly actual evapotranspiration, $\mathrm{ET}_{\mathrm{act}, j}$, is obtained by comparing its potential value, $\mathrm{ET}_{\mathrm{pot}, j}$, with the water effectively available for evapotranspiration:

$\mathrm{ET}_{\mathrm{act}, j}=\left\{\begin{array}{lll}\mathrm{ET}_{\mathrm{pot}, j}, & \text { if } & 0.7 P_{j}^{+} \geq \mathrm{ET}_{\mathrm{pot}, j}, \\ 0.7 P_{j}^{+}, & \text {if } & 0.7 P_{j}^{+}<\mathrm{ET}_{\mathrm{pot}, j} .\end{array}\right.$

\section{Case study}

The study domain is located in the North-Western Italian Alps and embraces a wide heterogeneous region, including catchments which strongly differ in mean elevation, altitude range and climatic characteristics. This variety of conditions involves a differentiation in the regime shapes, both in terms of precipitation and runoff. In fact, moving from the higher to the lower elevations, the shape of the runoff regime changes from one with a single peak, principally driven by snowmelt, to a curve with a second relative maximum during autumn, which is more typical of the middle-elevation catchments in this study area.

In the study domain, 40 catchments are selected (Fig. 2), with areas ranging from 40 to $3310 \mathrm{~km}^{2}$ and with elevation ranging between 117 and $4727 \mathrm{~m}$ a.s.l. (for more information on the study basins and their climatic characteristics, see the supplementary material and Bartolini et al., 2011a).

The basins are preliminarily checked to identify possible anthropogenic disturbances in runoff seasonality. In particular, we examine the presence of dams and flow regulation infrastructures, that may affect the regime shape by reducing the discharge variability. To this aim we introduce a reservoir index, $\mathrm{RI}=V_{\mathrm{l}} / V_{\mathrm{w}}$, defined as the ratio between the sum of the total retention volumes of the artificial lakes located within the basin, $V_{1}$, and the average water volume that flows at the basin outlet in a year, $V_{\mathrm{w}}$. A threshold value of RI equal to 0.25 is chosen to characterize the transition from an undisturbed to a disturbed regime. Only for river Toce at Cadarese $(R I=0.29)$ the condition on the RI index is not satisfied. Consequently, the final set of catchments used in the model application is composed of 39 elements. The second basin in terms of larger RI value is river Orco at Ponte Canavese, with $\mathrm{RI}=0.14$. 
To run the model, precipitation and temperature mean monthly values are used as meteorological forcings. In particular, the variability of temperature with elevation and geographic position is explicitly considered using maps of mean monthly temperatures obtained at $1 \mathrm{~km}^{2}$ grid resolution by Claps et al. (2008). In that study, the authors spatialized average monthly temperatures by means of a multi-regression approach based on elevation, latitude, distance from the sea, orientation and topographic concavity. However, it is worth noting that, if gridded temperature data were not available in the region of interest, elevation data could be used as a proxy of temperature through the use of suitable values of the lapse rate (see e.g., Allamano et al., 2009a). The necessary geographic parameters, namely latitude, longitude and elevation, are obtained at a $1 \mathrm{~km}$ resolution using the digital elevation model GTOPO30, developed by the United States Geological Survey (USGS, 2009). Observed runoff regimes, computed as monthly runoff averages, and multiyear monthly time series serve for the evaluation of the model performances.

\subsection{Correction of precipitation}

Basin mean monthly precipitation data are used in the model to define the total amount of water available and are uniformly divided among cells. However, basin precipitation is largely uncertain because it is the result of the spatialization of point-precipitation measurements, that are in turn affected by undercatch by wind effects, evaporation, wetting, splashing, blowing and drifting snow (e.g., Sevruk, 1983). These problems are exacerbated in mountainous areas, where the measurement network density is often inadequate to detect the small scale features of precipitation induced by the complex orography (Milly and Dunne, 2002). As a consequence, an imbalance between measured annual precipitation and runoff, the first being sometimes smaller than the latter, can be observed in some cases (Valery et al., 2010). A preliminary analysis on the data of our study domain reveals that measured annual precipitation is smaller than total runoff in 5 catchments (the hatched ones in Fig. 2). Considering also a preliminary estimate of mean annual evapotranspiration, the precipitation underestimation becomes even more critical, with 33 out of 39 basins that would turn out to have a negative water balance (i.e., annual runoff larger than the sum of measured precipitation and evapotranspiration, grayshaded basins in Fig. 2). This is a crucial clue that precipitation is underestimated, and should be suitably corrected to improve the model performances.

Given these premises, a two-step procedure is implemented in the model for the correction of the monthly precipitation bias. Firstly, the model is run by assigning fixed values to the model parameters. In particular, the standard deviation of daily temperature $\sigma$ is assumed to be $3^{\circ} \mathrm{C}$ and the melting rate $c$ is set to $0.7 \mathrm{~mm} /{ }^{\circ} \mathrm{C}^{2}$ day, corresponding, for $T_{j}^{+}=5^{\circ} \mathrm{C}$, to a melt factor of $3.5 \mathrm{~mm} /{ }^{\circ} \mathrm{C}$ day, analogous

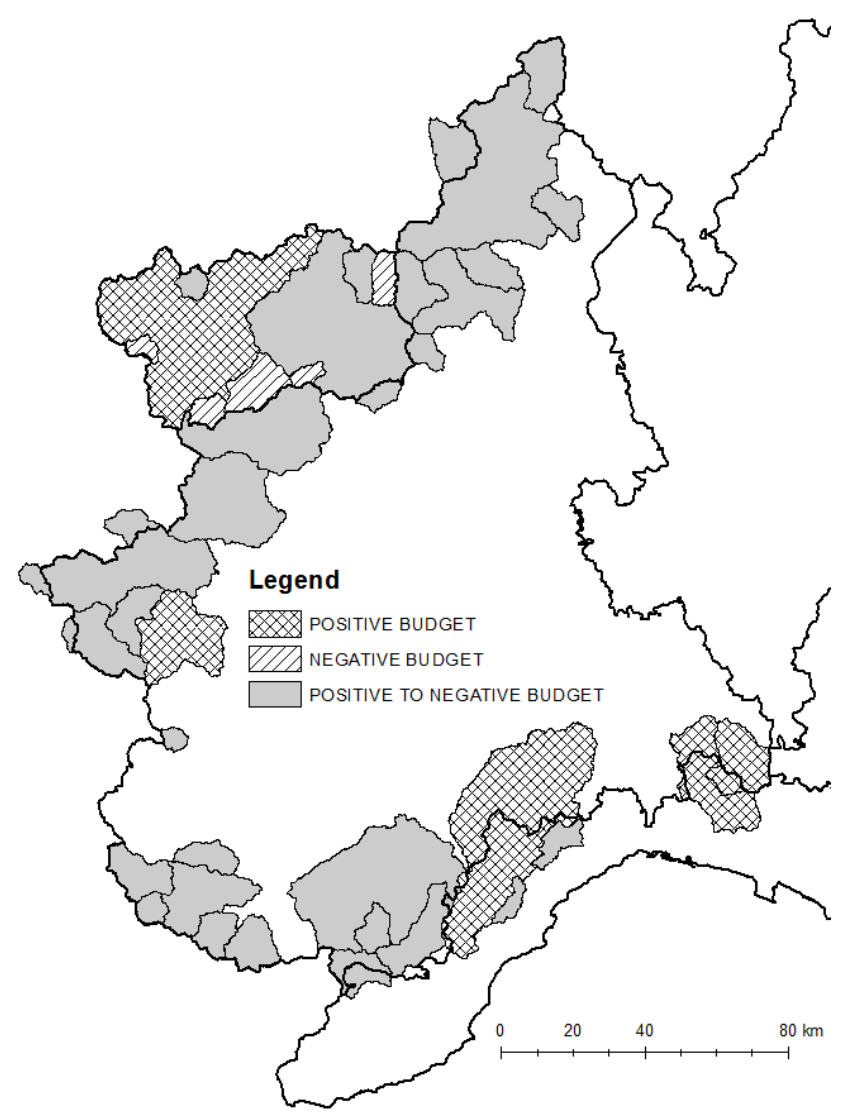

Fig. 2. Study domain and catchments used for the model application. Hatched (cross-hatched) basins are characterized by a negative (positive) budget (i.e., the difference between annual precipitation and runoff). Gray-shaded areas indicate basins with positive budget that becomes negative when accounting for evapotranspiration losses (i.e., $P-R-\mathrm{ET}_{\text {act }}$ ).

to the values proposed by the US Army Corps of Engineers (1998, chapter 6).

The model bias in runoff estimation,

$b=R_{\text {tot }, \mathrm{obs}}-R_{\mathrm{tot}, \mathrm{sim}}$,

is calculated as the difference between the annual simulated ( $\left.R_{\text {tot,sim }}\right)$ and observed ( $\left.R_{\text {tot,obs }}\right)$ runoff. Within the average year, total inflow (i.e., precipitation) is expected to equal the outflow (i.e., runoff and evapotranspiration). For this reason, we assume that the model bias is only due to precipitation undercatch. Adjusted monthly precipitation, $P_{\mathrm{adj}, j}$, is thus obtained as a function of the model bias according to the expression

$P_{\text {adj }, j}=P_{j}+\frac{b}{12}$.

The bias in Eq. (13) has been observed not to significantly vary in the model parameter domain. This is probably due to the fact that both parameters ( $c$ and $\sigma$ ) principally affect the timing of the phenomena involved in runoff formation (i.e., 


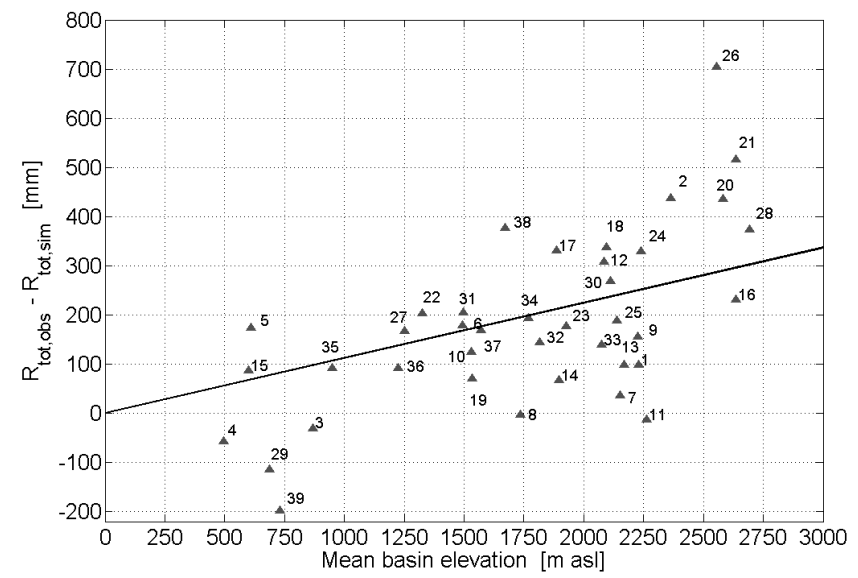

Fig. 3. Linear regression between mean basin elevation $h$ and model bias $b=R_{\mathrm{tot}, \mathrm{obs}}-R_{\mathrm{tot}, \mathrm{sim}}$ for the reference run. Dark triangles represent the model bias for each basin. The numbers refer to the basin-ID, as reported in the table in the supplementary material. The regression is significant with a level $\alpha=0.01$ and a coefficient of determination $R_{\text {adj }}^{2}=0.676$.

the snowmelt peak and the beginning of the snow season) rather than the annual water volumes. As a consequences, $b$ remains almost unchanged with variations of $c$ and $\sigma$, which allows us to keep it constant in the calibration run.

Since we are interested in applying the model also in ungauged basins, where no runoff data are available, the dependence of $b$ on geomorphic parameters should be studied. The analysis of the model bias shows that $b$ increases with the mean basin elevation (see Fig. 3), consistently with the common notion that the undercatch increases when precipitation falls as snow. Precipitation correction in Eq. (14) can thus be generalized by substituting the model bias $b$ with $b^{*}$, obtained by a linear regression of model bias on mean basin elevation $h$ (Fig. 3). The regression is constrained to the origin, so that no negative correction is applied to measured precipitation. For the Western Italian Alps we obtain

$b^{*}=0.112 \cdot h$,

where $b^{*}$ is in $\mathrm{mm}$ and $h$ in $\mathrm{m}$ a.s.l. The regression is significant since the slope of the regression line passes the T student test with a significance level $\alpha=0.01$.

\subsection{Parameter calibration}

The parsimony in the model structure is reflected in the fact that the model has only two parameters to be calibrated, namely the temperature standard deviation, $\sigma$, and the snowmelt rate, $c$. The storm runoff, instead, is not considered as a parameter since its variability does not significantly affect the quality of the reconstructed regimes over the study domain (see Bartolini et al., 2011a). The optimal values for $\sigma$ and $c$ are chosen in the calibration run, where these parameters are allowed to vary in a wide range, in order to assess

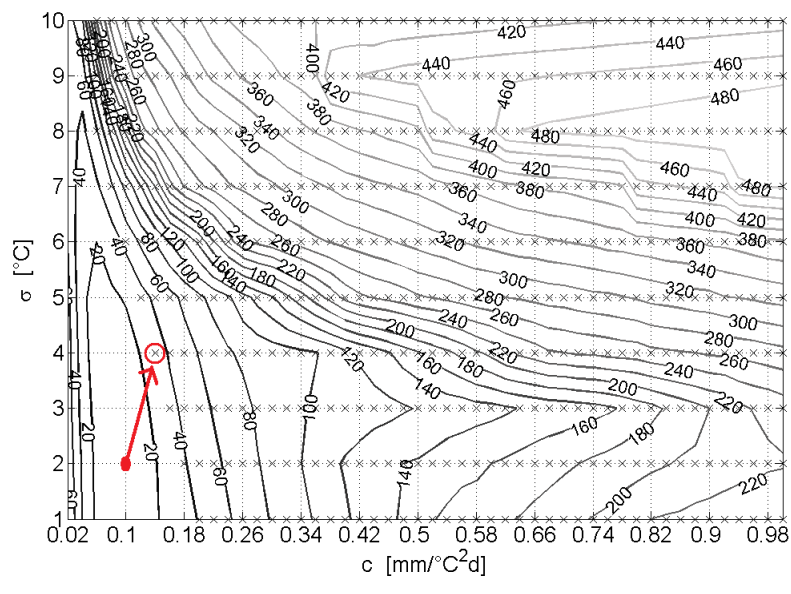

Fig. 4. MAE sensitivity to the values of $c$ and $\sigma$ for river Evançon at Champoluc (local scale application of the water balance model). Crosses represent the parameter combinations that fulfill the condition over the depletion of the snow storage.

model sensitivity. More specifically, $\sigma$ takes values in the range $1-10^{\circ} \mathrm{C}$ and $c$ in the interval $0.02-1 \mathrm{~mm} /{ }^{\circ} \mathrm{C}^{2}$ day.

Two different approaches for parameter calibration are followed, one considering a basin-specific and the other a regional point of view. In both cases, the mean absolute error

$\operatorname{MAE}(c, \sigma)=\frac{1}{12} \cdot \sum_{j=1}^{12}\left|R_{\mathrm{obs}, j}-R_{\mathrm{sim}, j}\right|$

is minimized, being $R_{\mathrm{obs}, j}$ and $R_{\mathrm{sim}, j}$ the observed and simulated values of monthly average runoff, respectively. In particular, the basin-specific calibration minimizes the MAE for each basin, providing locally optimal parameter values. The regional calibration procedure, instead, considers the whole set of catchments and seeks the combination of parameters that minimizes the global error, obtained by combining the MAE of each basin. This condition is considered with the aim of extending the application of the method to ungauged basins, once the suitability of taking spatially uniform parameters is assessed. In detail, the regional calibration process requires the following steps: (i) $n=500$ combinations of parameters are considered: $\sigma$ is varied between 1 and $10^{\circ} \mathrm{C}$ in steps of $1{ }^{\circ} \mathrm{C}$ and $c$ from 0.02 to $1 \mathrm{~mm} /{ }^{\circ} \mathrm{C}^{2}$ day in steps of $0.02 \mathrm{~mm} /{ }^{\circ} \mathrm{C}^{2} \mathrm{day}$; (ii) the $\mathrm{MAE}_{m, i}$ is calculated for each basin $m$ and for each parameter combination $i$; (iii) for each basin $m$, a rank $r_{m, i}$ is assigned to the parameter combination $c_{i}, \sigma_{i}$ where $\operatorname{MAE}\left(c_{i}, \sigma_{i}\right)$ is the $r$-th smallest value in the set of $n$ possible values; (iv) the average rank $\overline{r_{i}}$ is calculated as $\overline{r_{i}}=1 / 39 \sum_{m=1}^{39} r_{m, i}$ for each parameter combination; (v) the parameter combination producing the smaller $\bar{r}$ value is selected as the regional set of calibrated parameters.

The use of a ranked error indicator instead of the simple regional average MAE allows one to assign the same weight to all the basins considered. In fact, the MAE is a dimensional 

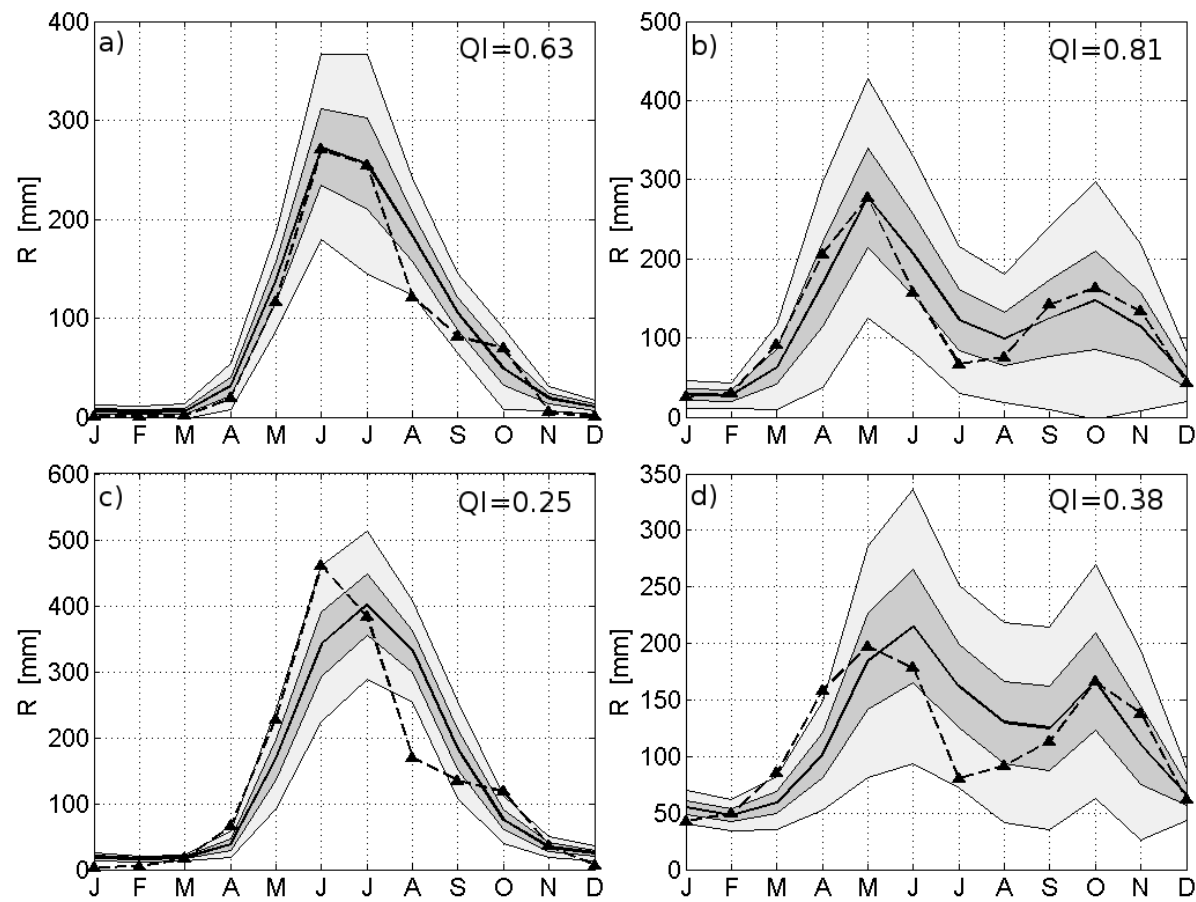

Fig. 5. Application at the local scale. Observed (solid line) and simulated (dashed line) runoff regimes. Dark (light) grey area represents the confidence bands of the observed runoff at $40 \%$ (80\%). (a) Savara at Eau Rousse; (b) Sesia at Ponte Aranco; (c) Rutor at Promise; (d) Toce at Candoglia. In the upper left corner of each panel a measure for the model performances, the Quality Index QI, is reported.

error statistic and, as such, it is affected by the size of the basins and by the entity of total annual runoff.

Finally, to avoid progressive snow accumulation over time, a condition on the parameter space is imposed. This condition requires the snow storage to empty at the end of the water year, so that the total annual inflow equals the outflow, with the exception of very high-elevation areas, where snow can persist even during summer. Residual snow is then allowed in the portion of basin higher than $3000 \mathrm{~m}$ a.s.l. The parameter combinations that do not allow the model to match this requirement are eliminated. An example is reported in Fig. 4, showing the MAE variability in the parameter space for river Evançon at Champoluc, as results from the basin-specific application of the water balance. Contour lines represent the MAE variability considering all the possible $(n=500)$ parameter combinations, while crosses identify the parameter combinations that fulfill the condition on the snow storage depletion. It is found that the parameters corresponding to the global minimum (i.e., $c=0.1 \mathrm{~mm} /{ }^{\circ} \mathrm{C}^{2}$ day and $\sigma=2{ }^{\circ} \mathrm{C}$ ) do not allow the complete melt the snow accumulated during the cold season. Therefore, in order to fulfill the snow depletion condition, the optimum parameter set is selected on the boundary of the surface defined by the crosses (red circle in Fig. 4).

\section{Results}

\subsection{Application at the local scale}

The water balance model is first applied and tested at the local scale (i.e., basin-specific application). This means that the local precipitation correction (i.e. dependent on the locally determined model bias) and the basin-specific calibration of the parameters are used.

The effectiveness of the reconstructed runoff regime is quantified by a quality index QI (see Appendix A for more details). This indicator varies between 0 , which stands for a poor agreement between observed and simulated runoff, and 1 , which indicates a perfect reconstruction of the observed values.

Figure 5 shows good (poor) quality results in the upper (lower) panels, respectively for high-elevation snowdominated catchments (Fig. 5a: Savara at Eau Rousse and 5c: Rutor at Promise) and for middle-elevation basins (Fig. 5b: Sesia at Ponte Aranco and 5d: Toce at Candoglia). Dark (light) gray-shaded areas show the $40 \%$ (80\%) confidence bands, calculated using the quantile function under the hypothesis of normality, as $R_{j, \mathrm{obs}} \pm 0.53 \sigma_{R, j}\left(R_{j, \mathrm{obs}} \pm\right.$ $1.28 \sigma_{R, j}$ ), where $\sigma_{R, j}$ is the standard deviation of the observed runoff in month $j$, calculated from the original time series.

Overall, the simulated runoff regimes reproduce quite well the observed ones, also considering the difficulty in dealing 

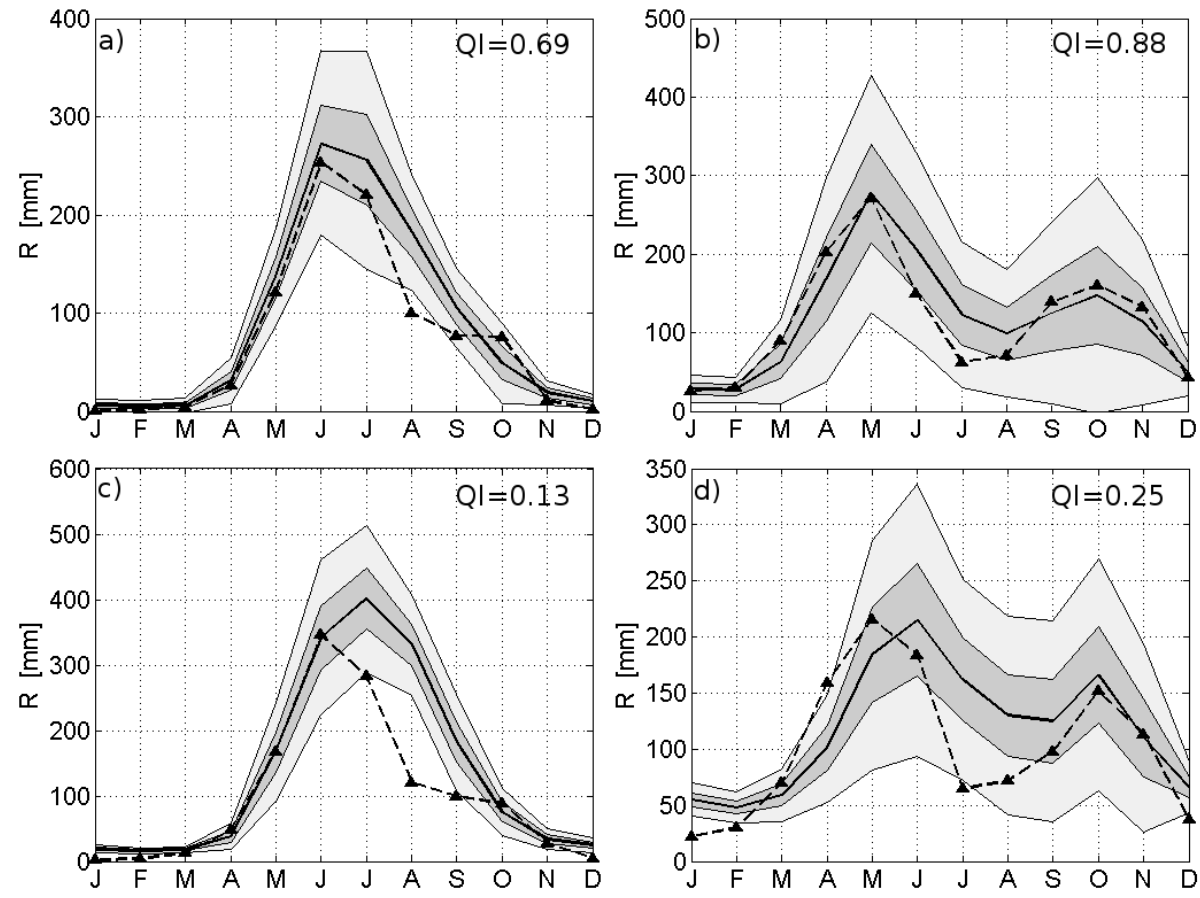

Fig. 6. Application at the regional scale. Observed (solid line) and simulated (dashed line) runoff regimes. Dark (light) grey area represents the confidence bands of the observed runoff at $40 \%$ (80\%). (a) Savara at Eau Rousse; (b) Sesia at Ponte Aranco; (c) Rutor at Promise; (d) Toce at Candoglia. In the upper left corner of each panel a measure for the model performances, the Quality Index QI, is reported.

with very different regime shapes. However, it is possible to detect systematic errors, in that most of the basins are characterized by a runoff overestimation in October and by an underestimation in August or July. With respect to the overestimation, it is important to notice that in October mean measured precipitation is higher than measured runoff. Being the evapotranspiration fluxes of minor importance during the fall season, a possible explanation for this overestimation is that, in the real system, this water surplus probably feeds the soil storage and it is released as runoff in the following months. Also the summer runoff underestimation can possibly be a consequence of the absence of a groundwater storage in the model framework. In fact, the water stored in the soil could partially feed runoff in the summer. In this respect, the hypotheses of taking into account a fraction of rainfall as storm runoff constitutes a simple method to limit this error and to attain a compromise between the introduction of a specific module to account for the groundwater effect and an increase in the number of parameters.

\subsection{Application at the regional scale}

When no measured runoff data are available, the water balance can be applied at the regional scale using the generalized precipitation correction defined by Eq. (15) and the regional parameter calibration procedure.

The parameters achieving the best average rank are $\sigma=$ $3{ }^{\circ} \mathrm{C}$ and $c=0.22 \mathrm{~mm} /{ }^{\circ} \mathrm{C}^{2}$ day. In this case, the melting rate is smaller than $0.7 \mathrm{~mm} /{ }^{\circ} \mathrm{C}^{2}$ day, which is the reference value (see Sect. 3.1) used in the first step of model application. This may be related to the time scale of the application, which is monthly rather than daily as in standard degree-day approaches, so that considerations on the temperature conditions just before snowmelt (i.e., antecedent snowpack energy or cold content) cannot be taken into account. In any case, the range of variability of melt factors reported in the literature is extremely wide (US Army Corps of Engineers, 1998).

Figure 6 presents the observed and simulated runoff regimes in the same basins shown in Fig. 5. The highest QI is associated with river Sesia at Ponte Aranco (Fig. 6b). On the contrary, Fig. 6d shows the runoff regime for river Toce at Candoglia, a middle-elevation catchment in which the performances of the model are particularly poor. In Fig. 6a, the average runoff seasonality of Savara at Eau Rousse, that is an high-elevation catchment, is presented. It shows a good agreement between observed and simulated curves during the first part of the year (from January to June) and an important runoff underestimation during the summer (July and August). The same error, even more significant, is evident in Fig. $6 c$ for the case of river Rutor at Promise. In this last case, the simulated regime presents a further incongruence in that the peak anticipates of 1 month the timing of the observed runoff peak. It is interesting to notice that river Toce at Candoglia and river Rutor at Promise correspond, in Fig. 3, to the points 38 and 26. Since these points (representing the 
model bias) are located far from the regression line used in the precipitation correction, one may conclude that the poor performances of the model are also contributed to by underestimation of the precipitation correction.

Overall, it appears that the water balance model, when applied at the regional scale, is still able to reproduce the regime shapes recognizing the different mechanisms of runoff formation. However, the regional application, which has the advantage of requiring few data and is suitable to be applied in ungauged catchments, leads, as expected, to generally poorer model performances.

Figure 7 shows the quality indices QI related to the basinspecific (light gray) and the regional (dark gray) scale application of the model. This representation is suitable to identify the basins where the model better reproduce the mean water balance and can be used as a tool to concisely present the results for a wide number of basins. However, due to its dependence on the error quantiles (see Appendix A for more details), the QI can not be used to compare different model applications (i.e., local vs regional application).

\section{Discussion}

To attain a parsimonious, yet realistic, representation of the runoff regime in high-elevation basins, various assumptions have been undertaken in the development of the proposed water balance model. Firstly, the structure of the balance equation (Eq. 1) implies that runoff reaches the outlet within one month from precipitation. As a consequence, the water balance is suitable to be applied to small and mediumsize basins. Moreover, given that the model is conceived for catchments characterized by the presence of the snow storage, it is suitable to be used at high-elevation sites. Other assumptions are made explicit in the model formulation, namely: (i) a probabilistic representation of the sub-monthly temperature variability; (ii) the presence of a rainfall fraction SR, unavailable for evapotranspiration, that directly contributes to runoff; (iii) a quadratic dependency of snowmelt on temperature; and (iv) the adjustment of average annual basin precipitation dependent on the mean annual observed runoff $R_{\mathrm{tot}, \text { obs }}$ or, if not available, on mean basin elevation. In the following, the motivations behind these hypotheses are discussed, along with some considerations on their consequences.

Because of its influence on snow dynamics, temperature is, beside precipitation, the main triggering variable of runoff formation in mountainous basins. For this reason, to properly describe the dynamics of snow accumulation and melting, the temperature sub-monthly variability has been modelled through a logistic distribution (Eq. 2). To test this hypothesis, an alternative model structure, called TEST1, that considers a constant monthly temperature, is developed. Figure 8a compares the MAE of the model proposed in this study (on the horizontal axis) to that obtained with the TEST1 model

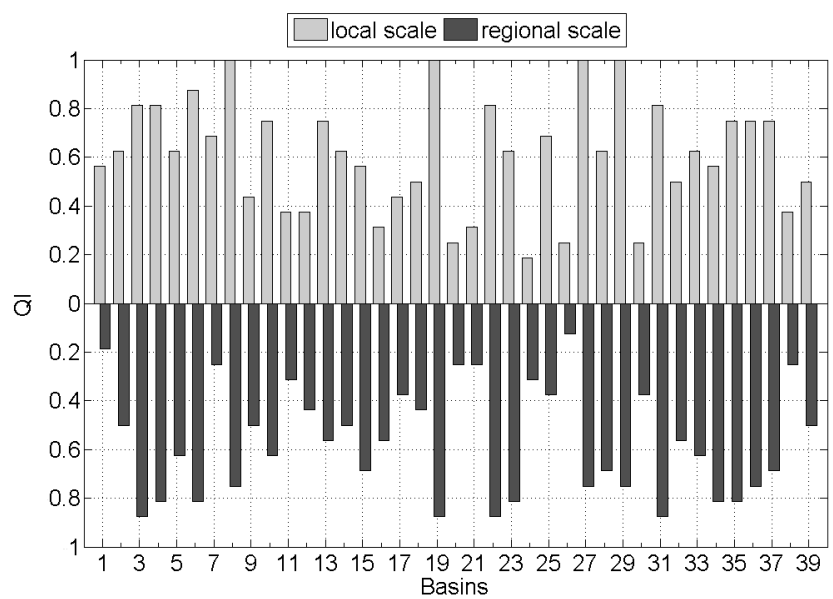

Fig. 7. Summary of the Quality Index QI obtained with the model application at the catchment scale (light gray) and at the regional scale (dark gray). The basin numbers refer to the table in the supplementary material.

structure (on the vertical axis). Both models are applied at the local scale, and each point represents a basin in the study region. Since the majority of points is located above the 1:1 line, one can conclude that taking into account the submonthly variability of temperature significantly improves the performances of the model. This was expected, since the TEST1 model has less parameters than the standard model, but the improvement in the performances is large enough to justify, in our opinion, the additional model parameter. When the partitioning of the months into periods of positive and negative temperature is allowed, two main consequences can be observed, depending on the catchment altitude: (i) at high elevations, during the cold season, the snow storage assumes smaller proportions, because part of the monthly precipitation is allowed to contribute to runoff at the expense of the snow storage; (ii) at middle elevations the parameter $\sigma$ allows one to simulate the coexistence of snow accumulation, melt and evapotranspiration even when winter monthly temperatures are slightly positive.

Another assumption of the water balance model consists, as previously mentioned, in considering a fraction of monthly rainfall, namely the storm runoff SR, that is not available for evapotranspiration. This water amount is used to roughly separate volumes related to heavy storms and infiltration into the soil, respectively. Using a diagnostic plot similar to the one shown before, the storm runoff assumption is tested against the hypothesis of SR $=0$ (model TEST2 in Fig. 8b, vertical axis). TEST2 differs from the original water balance in that all the monthly liquid rainfall firstly feeds the evapotranspiration, while only the remaining part contributes to runoff formation. The MAE associated to the model TEST2 is larger than the MAE associated to the model we propose in 37 basins out of 39 , indicating that considering a fraction of storm runoff is a reasonable assumption. 

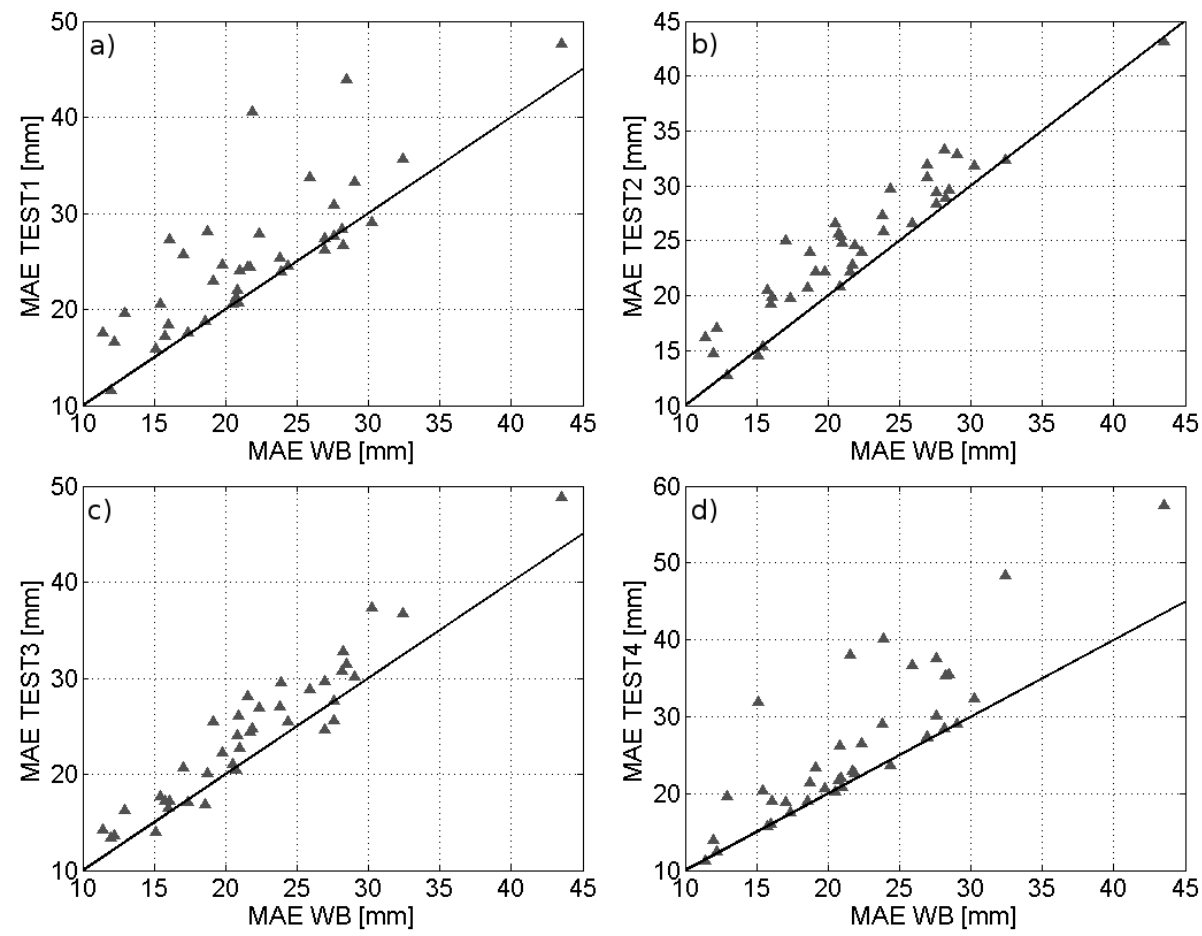

Fig. 8. Evaluation of the model assumptions, local scale application. On the horizontal axis there is the MAE of the water balance model. On the vertical axis the MAE of the model: (a) without temperature variability; (b) without storm runoff; (c) with snowmelt modelled by a linear degree-day approach; (d) without precipitation correction.

Moreover, in this case, the comparison is fair, because the two model structures have the same number of parameters. On a more physical basis, the positive effect of SR is important during the warm season, when net precipitation (i.e., the difference between the quantity $0.7 P^{+}$and evapotranspiration $\mathrm{ET}_{\text {act }}$ ) is very low or equal to zero, and the simulated runoff is composed only by snowmelt, if any, and by SR.

In Fig. 8c a comparison between the use of the parabolic law for snowmelt (Eq. 6) and the standard (i.e., linear) degree-day approach (TEST3) is reported. Again, almost all the points are above the 1:1 line, demonstrating the ability of the proposed framework to better simulate snowmelt dynamics. This result can be explained by considering that a common drawback of the degree-day method is related to the use of a constant (i.e., not depending on the season) melt factor (see, e.g., chapter 6 in Singh and Singh, 2001). In contrast, the parabolic law allows one to simulate higher (lower) snowmelt rates in correspondence with largely (slightly) positive temperatures, with the advantage of requiring only one parameter.

The last model assumption to discuss is related to the way we quantify the mean basin precipitation undercatch, whose characterization is fundamental in high-elevation basins (Valery et al., 2010). In the case of the basin-specific application, it is assumed that the correction depends only on the observed runoff and, consequently, on the model bias. The effects of this assumption are shown in Fig. 8d, which reports the mean absolute error of the model with (without) precipitation correction on the horizontal (vertical) axis. It can be noticed that the MAE, in this latter case, is significantly lower for almost all the basins.

\section{Conclusions}

A simple and parsimonious water balance model, particularly conceived for high-elevation regions, has been developed, primarily to reconstruct the shape of the runoff regime and the timing of its peaks. The model is suitable to be applied in small and medium size mountain basins and proves to be able to discern between different mechanisms of runoff formation in the study domain. The adoption of such a simple model framework is motivated by the aim of identification of the main governing mechanisms affecting the water balance at the monthly time-scale in high-elevation basins. Moreover, the parsimony approach is essential in view of the extension of the proposed method to ungauged catchments.

The model proves to be able to reconstruct regime shapes and timing in most of the cases. However, some problems remain concerning the regime reconstruction in specific periods of the year. In particular, most of the basins show runoff overestimation in October and underestimation during July or August. These systematic errors seem to be due principally to the highly simplified model structure. 
Concerning the possibility of applying and calibrating the model also in ungauged contexts, the regional parameter calibration procedure and the generalized precipitation adjustment allow one to move from the local scale to the regional scale, with the opportunity to investigate, with a simple and parsimonious approach, the interplay among the different variables in the water balance. However, when the regional balance is applied, the summer underestimation becomes more critical for high-elevation basins, indicating that the generalized precipitation correction needs to be ameliorated in terms of water volumes and seasonality. With respect to other regionalization procedures, the use of a water balance model to reconstruct runoff seasonality allows one to obtain not only runoff regimes but also the average volumes of actual evapotranspiration, SWE and snowmelt, generally not available at the basin scale, which are fundamental to understand and reproduce the rainfall-runoff mechanisms when snow dynamics are involved (an example is provided in Bartolini et al., 2011b). Moreover, due to the driving role that temperature has in triggering snow accumulation, melt and evapotranspiration, the model is suitable for preliminary investigation on the possible effects that global warming may have on the physical processes of the hydrologic cycle.

\section{Appendix A}

\section{Measure of model quality}

In order to evaluate the performances of the model, a quality index QI is introduced. The index is computed as a function of four quality indicators,

$\mathrm{QI}=f\left(\sigma_{R, j}, \mathrm{MAE}, b, t_{\text {peak }}\right)$,

that are the monthly measured runoff standard deviation $\sigma_{R, j}$, the mean absolute error MAE, the model bias $b$, and the month $t_{\text {peak }}$ in which the runoff peak occurs. The choice of a combination of measures is motivated by the fact that the assessment of the similarity between two curves, namely the simulated and observed mean runoff, has to take into account several factors: the volume imbalance (i.e., bias), the differences between the shape of the curves (i.e., the amplitude of the oscillations), represented by the MAE, and the model capability in predicting the timing of the runoff peak. Moreover, since the evaluation of the model considers only mean seasonal curves, also the year to year runoff variability, represented by the standard deviation of monthly runoff $\sigma_{R, j}$, has to be considered. It is fair to assume that when the simulated runoff falls inside the observed variability range the model performance is satisfactory.

The calculation of the QI requires a scoring of these quality indicators. The method is described hereinafter. (1) The monthly runoff standard deviation $\sigma_{R, j}$ is used to calculate the $80 \%$ confidence bands under the hypothesis of normality as $R_{\mathrm{obs}, j} \pm 1.28 \sigma_{R, j}$. These values are used as a threshold to count the number of months where simulated runoff falls outside the bands. The scores $1,0.75,0.5,0.25$ and 0 are then assigned, to each basins, respectively for $1,2,3$, and 5 or more months characterized by mean monthly values outside the confidence bands. (2) MAE and bias are divided into 5 equiprobable classes, whose limits are their respective $0.2,0.4,0.6$ and 0.8 quantiles. A score varying from 1 to 0 (i.e., $1,0.75,0.5,0.25,0$ ) is assigned to each class. (3) The timing of the peak is evaluated by assigning a score 1 in case of perfect timing and 0.5 in case of an earlier or late (by greater or equal to 1 month) peak. For middle-elevation basins, where runoff regime is sometimes characterized by two maxima corresponding to the spring snowmelt and fall peaks, only the global maximum is considered. The QI is then obtained as the mean of the scores assigned to each factor.

For example, the simulated runoff regime of river Sesia at Ponte Aranco, obtained with the application of the water balance at the local scale (Fig. 5b), has the following characteristics: (i) the runoff never falls outside the confidence bands (score 1); (ii) the MAE is equal to $21.73 \mathrm{~mm}$ and corresponds to the third equiprobable class, whose limits are the 0.4 and the 0.6 quantiles (score 0.5); (iii) model bias $b=14.66 \mathrm{~mm}$ falls in the fourth class, defined by the 0.2 and the 0.4 quantiles (score 0.75); (iv) the months of the simulated and the observed peak are concordant (score 1). Averaging the scores assigned, one obtains QI $=0.88$, that is the value of the quality index assigned to this basin with respect to the local model application.

The quality index QI can be used to judge the quality of the reconstructed runoff regime by comparison with the other QI indices obtained using the same model structure. This means that, given the model results, the QI can be used to discern basins where the simulated runoff well represents the measured one from basins where the water balance performances are poor. On the contrary, due to the mechanism of score assignment based on sample quantiles, which change depending on the model simulations, the QI cannot be used to compare the results of two different modelling frameworks (i.e., local versus regional scale).

\section{Supplementary material related to this article is available online at: http://www.hydrol-earth-syst-sci.net/15/1661/2011/ hess-15-1661-2011-supplement.pdf.}

Acknowledgements. The work was funded by the Italian Ministry of Education (CUBIST Project, grant 2007HBTS85, and grant 2008KXN4K8).

Edited by: P. A. Troch 


\section{References}

Abramowitz, M. and Stegun, I. A.: Handbook of Mathematical Functions with Formulas, Graphs, and Mathematical Tables, Dover, New York, Tenth Dover printing edition, 1964.

Adam, J. C., Hamlet, A. F., and Lettenmaier, D. P.: Implications of global climate change for snowmelt hydrology in the twenty-first century, Hydrol. Processes, 23, 962-972, doi:10.1002/hyp.7201, 2009.

Allamano, P., Claps, P., and Laio, F.: An analytical model of the effects of catchment elevation on the flood frequency distribution, Water Resour. Res., 45, W01402, doi:10.1029/2007WR006658, 2009a.

Allamano, P., Claps, P., and Laio, F.: Global warming increases flood risk in mountainous areas, Geophys. Res. Lett., 36, L24404, doi:10.1029/2009GL041395, 2009b.

Alley, W. M.: Water balance models in one-month ahead streamflow forecasting, Water Resour. Res., 21, 597-606, 1985.

Bartolini, E., Allamano, P., Laio, F., and Claps, P.: Interactive comment on "Runoff regime estimation at high-elevation sites: a parsimonious water balance approach" by E. Bartolini et al., Hydrol. Earth Syst. Sci. Discuss., 8, C921-C937, 2011a.

Bartolini, E., Allamano, P., Laio, F., and Claps, P.: Interactive comment on "Runoff regime estimation at high-elevation sites: a parsimonious water balance approach" by E. Bartolini et al., Hydrol. Earth Syst. Sci. Discuss., 8, C645-C653, 2011 b.

Beniston, M., Diaz, H. F., and Bradley, R. S.: Climatic change at high elevation sites: an overview, Climatic Change, 36, 233-251, 1997.

Beven, K.: Changing ideas in hydrology - the case of physically based models, J. Hydrol., 105, 157-172, 1989.

Bras, R. L.: Hydrology, an introduction to hydrologic science, Addison-Wesley, New York, 1990.

Chow, V. T.: Handbook of applied hydrology, McGraw-Hill, New York, USA, 1964.

Claps, P., Giordano, P., and Laguardia, G.: Spatial distribution of the average air temperatures in Italy: quantitative analysis, J. Hydrol. Eng., 13, 242-249, 2008.

Collins, D. N.: Rainfall-induced high-magnitude runoff events in highly-glacierized Alpine basins, Hydrology, Water Resources and Ecology in Headwaters, Proceedings of the HeadWater'98 Conference, Merano, Italy, April 1998, IAHS Publication no. 248, 1998.

De Jong, C., Whelan, F., and Messerli, B.: Preface: The importance of a hydrological research framework for water balance studies in mountain basins, Hydrol Processes, 19(12), 2323-2328, 2005.

Eder, G., Fuchs, M., Nachtnebel, H. P., and Loibl, W.: Semidistributed modelling of the monthly water balance in an alpine catchment, Hydrol. Processes, 19, 2339-2360, 2005.

Gleick, P. H.: Methods for evaluating the regional hydrologic impacts of global climatic changes, J. Hydrol., 88, 99-116, 1986.

Henning, I. and Henning, D.: Potential evapotranspiration in mountain geoecosystems of different altitudes and latitudes, Mt. Res. Dev., 1, 267-274, 1981.

Hock, R.: Temperature index melt modelling in mountain areas, J. Hydrol., 282, 104-115, 2003.

Horton, P., Schaefli, B., Mezghani, A., Hingray, B., and Musy, A.: Assessment of climate-change impacts on alpine discharge regimes with climate model uncertainty, Hydrol. Processes, 20, 2091-2109, 2006.
Jasper, K., Calanca, P., Gyalistras, D., and Fuhrer, J.: Differential impacts of climate change on the hydrology of two alpine river basins, Clim. Res., 26, 113-129, 2004.

Johnson, N. L., Kotz, S., and Balakrishnan, N.: Continuous univariate distribution, vol. 2, Wiley series in Probability and Statistics, Wiley \& Sons, NY, USA, 2nd edition, 1995.

Kling, H., Furst, J., and Nachtnebel, H. P.: Seasonal, spatially distributed modelling of snow accumulation and melting for computing runoff in a long-term, large-basin water balance model, Hydrol. Processes, 20, 2141-2156, 2006.

Limbrunner, J. F., Vogel, R. M., and Chapra, S. C.: A parsimonious watershed model, in: Watershed models, edited by: Singh, V. P. and Frevert, D. K., CRC Press, Boca Raton, Florida, 2006.

Milly, P. C. D. and Dunne, K. A.: Macroscale water fluxes 1. Quantifying errors in the estimation of basin mean precipitation, Water Resour. Res., 38, 1205, doi:10.1029/2001WR000759, 2002.

Mouelhi, S., Michel, C., Perrin, C., and Andreassian, V.: Stepwise development of a two-parameter monthly water balance model, J. Hydrol., 318, 200-214, 2006.

Schaefli, B., Hingray, B., Niggli, M., and Musy, A.: A conceptual glacio-hydrological model for high mountainous catchments, Hydrol. Earth Syst. Sci., 9, 95-109, doi:10.5194/hess-995-2005, 2005.

Sevruk, B.: Correction of measured precipitation in the Alps using the water equivalent of new snow, Nord. Hydrol., 14, 49-58, 1983.

Singh, P. S. and Singh, V. P.: Snow and glacier hydrology, Water Science and Technology Library, Kluwer Academic Publishers, Dordrecht, The Netherlands, 2001.

Sivakumar, B.: Dominant processes concept, model simplification and classification framework in catchment hydrology, Stoch. Environ. Res. Risk Assess., 22, 737-748, 2008.

Stössel, F., Guala, M., Fierz, C., Manes, C., and Lehning, M.: Micrometeorological and morphological observations of surface hoar dynamics on a mountain snow cover, Water Resour. Res., 46, W04511, doi:10.1029/2009WR008198, 2010.

Thornthwaite, W. C.: An approach toward a rational classification of climate, Geogr. Rev., 38, 55-94, 1948.

US Army Corps of Engineers: Runoff from snowmelt, Department of the Army, Washington, DC 20314-1000 Manual, 1998.

US Geological Survey (USGS): GTOPO30, http://eros.usgs.gov/\#/ Find_Data/Products_and_Data_Available/gtopo30_info, 20 October 2009.

Valery, A., Andreassian, V., and Perrin, C.: Regionalization of precipitation and air temperature over high-altitude catchments learning from outliers, Hydrolog. Sci. J., 55, 928-940, 2010.

Wang, G., Xia, J., and Chen, J.: Quantification of effects of climate variations and human activities on runoff by a monthly water balance model: a casa study for the Chaobai river basin in northern China, Water Resour. Res., 26, 295-309, 2009.

Woods, R.: The relative roles of climate, soil, vegetation and topography in determining seasonal and long-term catchments dynamics, Adv. Water Resour., 26, 295-309, 2003.

Woods, R.: Analytical model of seasonal climate impacts on snow hydrology: continuous snowpacks, Adv. Water Resour., 32, 1465-1481, 2009.

Xia, Y. and Guoqiang, X.: Impacts of systematic precipitation bias on simulations of water and energy balance in northwest America, Adv. Atmos. Sci., 24, 739-449, 2007. 
$\mathrm{Xu}, \mathrm{C}$. Y. and Sing, V. P.: A review of monthly water balance models for water resources investigations, Water Resour. Manag., 12, 31-50, 1998.

$\mathrm{Xu}, \mathrm{C}$., Seibert, J., and Halldin, S.: Regional water balance modelling in the nopex area: development and application of monthly water balance models, J. Hydrol., 180, 211-236, 1996.
Zappa, M., Pos, F., and Strasser, U.: Seasonal water balance of an alpine catchment as evaluated by different methods for spatially distributed snowmelt modelling, Nord. Hydrol., 34, 179202, 2003.

Zierl, B. and Bugman, H.: Global change impacts on hydrological processes in alpine catchments, Water Resour. Res., 41, W02028, doi:10.1029/2004WR003447, 2005. 